\title{
Antibody-Functionalized Polymer Nanoparticle Leading to Memory Recovery in Alzheimer's Disease-like Transgenic Mouse Model
}

Dario Carradori, $\mathrm{PhD},{ }^{1, \dagger}$ Claudia Balducci, $\mathrm{PhD},{ }^{2, \dagger}$ Francesca Re, $\mathrm{PhD},{ }^{3, *}$ Davide Brambilla, $\mathrm{PhD},{ }^{1}$ Benjamin Le Droumaguet, $\mathrm{PhD},{ }^{4}$ Orfeu Flores, $\mathrm{PhD},{ }^{5}$ Alice Gaudin $, \mathrm{PhD},{ }^{1}$ Simona Mura, $\mathrm{PhD},{ }^{1}$ Gianluigi Forloni, $\mathrm{PhD},{ }^{2}$ Lara Ordoñez-Gutierrez, $\mathrm{PhD},{ }^{7}$ Francisco Wandosell, $\mathrm{PhD},{ }^{7}$ Massimo Masserini; $\mathrm{PhD},{ }^{3}$ Patrick Couvreur, $\mathrm{PhD},{ }^{1}$ Julien Nicolas, $\mathrm{PhD}{ }^{1, *}$ and Karine Andrieux, $\mathrm{PhD}^{8}$

${ }^{1}$ Institut Galien Paris Sud, CNRS UMR 8612, Univ Paris-Sud, Univ. Paris Saclay, ChâtenayMalabry, France.

${ }^{2}$ Istituto Mario Negri, I-20126 Milano, Italy.

${ }^{3}$ School of Medicine and Surgery, University of Milano-Bicocca, I-20900 Monza, Italy.

${ }^{4}$ Univ Paris-Est Creteil Val-de-Marne, CNRS UMR 7182, Institut de Chimie et des Matériaux Paris-Est, F-94320 Thiais, France

${ }^{5}$ Stab Vida, Madan Parque, Rua dos Inventores, P-2825-182, Caparica, Portugal.

${ }^{6}$ Centro de Biología Molecular Severo Ochoa CSIC-UAM \& CIBERNED, Madrid, Spain

${ }^{7}$ Faculté de Pharmacie de Paris, UTCBS, CNRS UMR 8258, Inserm U1022, Univ. Paris Descartes, Univ. Sorbonne Paris Cité, 4, avenue de l'observatoire, F-75006, Paris, France.

${ }^{\dagger}$ Equally contributing authors

*To whom correspondence should be addressed:

Francesca Re, School of Medicine and Surgery, University of Milano-Bicocca, I-20900 Monza, Italy. Tel.: +39 2644883 11; Email: francesca.re1@unimib.it

Julien Nicolas, Institut Galien Paris Sud, CNRS UMR 8612, Univ Paris-Sud, Faculté de Pharmacie, 5 rue Jean-Baptiste Clément, F-92296 Châtenay-Malabry, France. Tel.: +33146 8358 53; Email: julien.nicolas@u-psud.fr.

The authors state there are no conflicts of interest with this work. 


\section{Word count}

Abstract: 149; Manuscript: 4858; Number of references: 55; Number of Figures/Tables: 6

\section{Abstract}

Alzheimer's disease (AD) is a neurodegenerative disorder related, in part, to the accumulation of amyloid- $\beta$ peptide $(A \beta)$ and especially the $A \beta$ peptide $1-42\left(A \beta_{1-42}\right)$. The aim of this study was to design nanocarriers able to: (i) interact with the $A \beta_{1-42}$ in the blood and promote its elimination through the "sink effect" and (ii) correct the memory defect observed in AD-like transgenic mice. To do so, biodegradable, PEGylated nanoparticles were surfacefunctionalized with an antibody directed against $A \beta_{1-42}$. Treatment of AD-like transgenic mice with anti-A $\beta_{1-42}$-functionalized nanoparticles led to: (i) complete correction of the memory defect; (ii) significant reduction of the $A \beta$ soluble peptide and its oligomer level in the brain and (iii) significant increase of the $\mathrm{A} \beta$ levels in plasma. This study represents the first example of $A \beta_{1-42}$ monoclonal antibody-decorated nanoparticle-based therapy against $A D$ leading to complete correction of the memory defect in an experimental model of AD.

\section{Keywords}

Polymer Nanoparticles; Alzheimer's disease; antibody; blood-brain barrier; $\beta$-amyloid peptide 


\section{Background}

Alzheimer's disease (AD) is a neurodegenerative disease with the highest incidence compared to other types of dementia. ${ }^{1,2}$ Mid-2015, the World Health Organization (WHO) estimated that $\mathrm{AD}$ affected about 36 million people worldwide with an overall economic impact of nearly 818 billion USD per year. ${ }^{3}$ Although AD is the focus of intensive research, its pathogenesis remains only partially understood and there is still no cure available.

The two most prominent histopathological hallmarks of $\mathrm{AD}$ are extracellular plaques, mainly composed of amyloid- $\beta$ peptide $(\mathrm{A} \beta)$ species, and intracellular neurofibrillary tangles made of hyperphosphorylated $\tau$ protein. ${ }^{4}$ Several lines of evidence converge towards what is known as the "amyloid hypothesis", according to which the neurofibrillary tangles and the associated neurodegeneration are believed to be secondary to the accumulation of $A \beta$ species, which would result from the imbalance between the production of $\mathrm{A} \beta$ and its clearance from the brain. ${ }^{5}$ A considerable amount of knowledge has been accumulated since the first report of purification and characterization of $\mathrm{A} \beta$ species from the brain tissue of $\mathrm{AD}$ patients. ${ }^{6}$ It is now well known that $A \beta$ is produced by the proteolytic cleavage of a larger amyloid precursor protein (APP), a constitutively expressed transmembrane glycoprotein with still unclear functions. ${ }^{7,8}$ Under normal conditions, the non-amyloidogenic cleavage of APP by $\alpha$ - and $\gamma$ secretases predominates and generates different non-aggregating fragments. ${ }^{9}$ Alternatively, the proteolysis of the APP by the sequential enzymatic actions of $\beta$-site amyloid precursor protein-cleaving enzyme 1 (BACE1 or $\beta$-secretase) and $\gamma$-secretase leads to the production of $\mathrm{A} \beta$ of 37-42 amino acids found in the senile plaques of $\mathrm{AD}$ brains. ${ }^{10}$ Among the different species, the $A \beta$ peptide 1-42 $\left(A \beta_{1-42}\right)$ is believed to be the most representative and toxic species in AD physiopathology because of its high tendency to self-aggregate, ${ }^{11}, 12$ whereas the soluble $A \beta_{1-42}$ oligomer is toxic to neurons. ${ }^{13,14}$ 
$A \beta$ is indeed naturally prone to self-aggregation owing to its enriched sequence in hydrophobic residues. ${ }^{15,} 16$ It was recently shown that $A \beta$ oligomers, rather than the monomeric form or misfolded $\mathrm{A} \beta$ fibrils, are mainly responsible for neurotoxicity. ${ }^{10}$ Alongside $A \beta$ oligomerization and deposition, synaptic and neuritic injury occur, as well as alterations in neuronal ionic homeostasis, oxidative injury and altered kinase/phosphatase activities (responsible for the neurofibrillary tangles), which altogether ultimately lead to neuronal dysfunction and cellular death. ${ }^{17}$

In the past few years, a number of different therapeutic strategies against $\mathrm{AD}$ have been investigated, including: (i) inhibition/modulation of the secretase activity; (ii) enhancement of $\mathrm{A} \beta$ clearance from the brain with antibodies or nanoparticulate systems; (iii) decreasing of cholesterol levels (given the link between high cholesterol levels and AD incidence); (iv) chelation of metallic ions needed for $A \beta$ aggregation and (v) protection of neurons against synaptic dysfunction and degeneration. ${ }^{18-21}$ However, current treatments against AD (e.g., NMDA receptor antagonist, ${ }^{22}$ AchE inhibitors ${ }^{23}$ ) are solely palliative and limited to the alleviation of symptoms and behavioral disturbances. ${ }^{24,}{ }^{25}$ Lately, clearance of $A \beta$ from the brain was identified as one of the most ambitious strategies for potential treatment of AD. ${ }^{26}$ The physiological elimination of $A \beta_{1-42}$ peptide from the brain towards the blood has been shown to be promoted by receptors like low-density lipoprotein receptor related protein-1 (LRP1) and P-glycoprotein (P-gp).

Nanotechnology and its application to the biomedical field (usually termed nanomedicine) hold great hope for the treatment of severe diseases. ${ }^{27,}{ }^{28}$ So far, only three nanoparticulate systems with enhanced affinity for $\mathrm{A} \beta$ have been designed to counterbalance the deficient $A \beta$ clearance mechanism in vivo: (i) PEGylated liposomes bifunctionalized with a peptide deriving from the Apo E receptor-binding domain for blood-brain barrier (BBB) targeting and phosphatidic acid for $\mathrm{A} \beta$ binding, ${ }^{29,}{ }^{30}$ (ii) Apo E3-reconstituted high density 
lipoprotein (Apo E3-rHDL) $)^{31}$ and (iii) liposomes surface-functionalized by a monoclonal anti-A $\beta$ antibody. ${ }^{32}$ This latter study is very interesting owing to the high affinity and specificity of antibodies towards their targets (antigens), reducing off-site binding and preventing substantial decrease of the therapeutic efficiency. ${ }^{33}$ However, a proof of efficacy; that is the correction of the memory defect, was not investigated and thus, to date, no successful in vivo example of antibody-decorated nanoparticle-based therapy against AD leading to complete memory recovery has ever been reported, which would represent a crucial step forward.

Among the different classes of materials suitable for drug delivery purposes, biodegradable polymer nanoparticles have attracted much attention due to their safety, the flexibility offered by macromolecular synthesis methods, the wide range of (co)polymer compositions and the possibility to functionalize them for targeting and/or imaging purposes. ${ }^{34}$ In this context, poly(alkyl cyanoacrylate) (PACA) nanoparticles represent a wellestablished drug delivery platform leading to promising results against different pathologies such as cancer or infections ${ }^{35-38}$ and whose degradation is catalyzed in vivo by esterases. ${ }^{39}$ Importantly, doxorubicin-loaded poly(isohexyl cyanoacrylate) nanoparticles ${ }^{40}$ are currently in phase III clinical trial for the treatment of MDR resistant hepatocarcinoma. Moreover, it was evidenced that PEGylated nanoparticles of poly[hexadecyl cyanoacrylate-comethoxypoly(ethylene glycol) cyanoacrylate] (P(HDCA-co-MePEGCA)) (denoted as NPs in this paper) exhibited affinity towards the $A \beta_{1-42}$ peptide, as observed by surface plasmon resonance (SPR), where preferential interaction between PEG chains and A $\beta$ have been established. ${ }^{41}$ This affinity was further strongly increased via 'click chemistry'-based surfacefunctionalization by different $\mathrm{A} \beta$ targeting ligands such as curcumin derivatives (CurcuminNPs) and anti-A $\beta_{1-42}$ monoclonal antibody (anti-A $\beta_{1-42}$-NPs, see Figure 1). ${ }^{42}$ SPR experiments evidenced an enhanced affinity towards $A \beta_{1-42}$ monomers (and fibrils) thanks to this surface 
modification, with $K_{\mathrm{D}}$ values of $0.8 \mu \mathrm{M}$ (and $0.3 \mu \mathrm{M}$ ) and $\sim 700 \mathrm{pM}$ (and $\sim 300 \mathrm{pM}$ ) for Curcumin-NPs and anti-A $\beta_{1-42}$-NPs, respectively. ${ }^{42}$ Thus, anti-A $\beta_{1-42}$-NPs appeared as the most promising system to target $A \beta$ peptide to inhibit its aggregation, to favor its clearance from the brain and to finally decrease its neurotoxicity. However, the robustness of this strategy and therefore its potential as therapy against AD mainly depend on whether these nanocarriers can demonstrate improved biological performances in vivo in AD-like animal models.

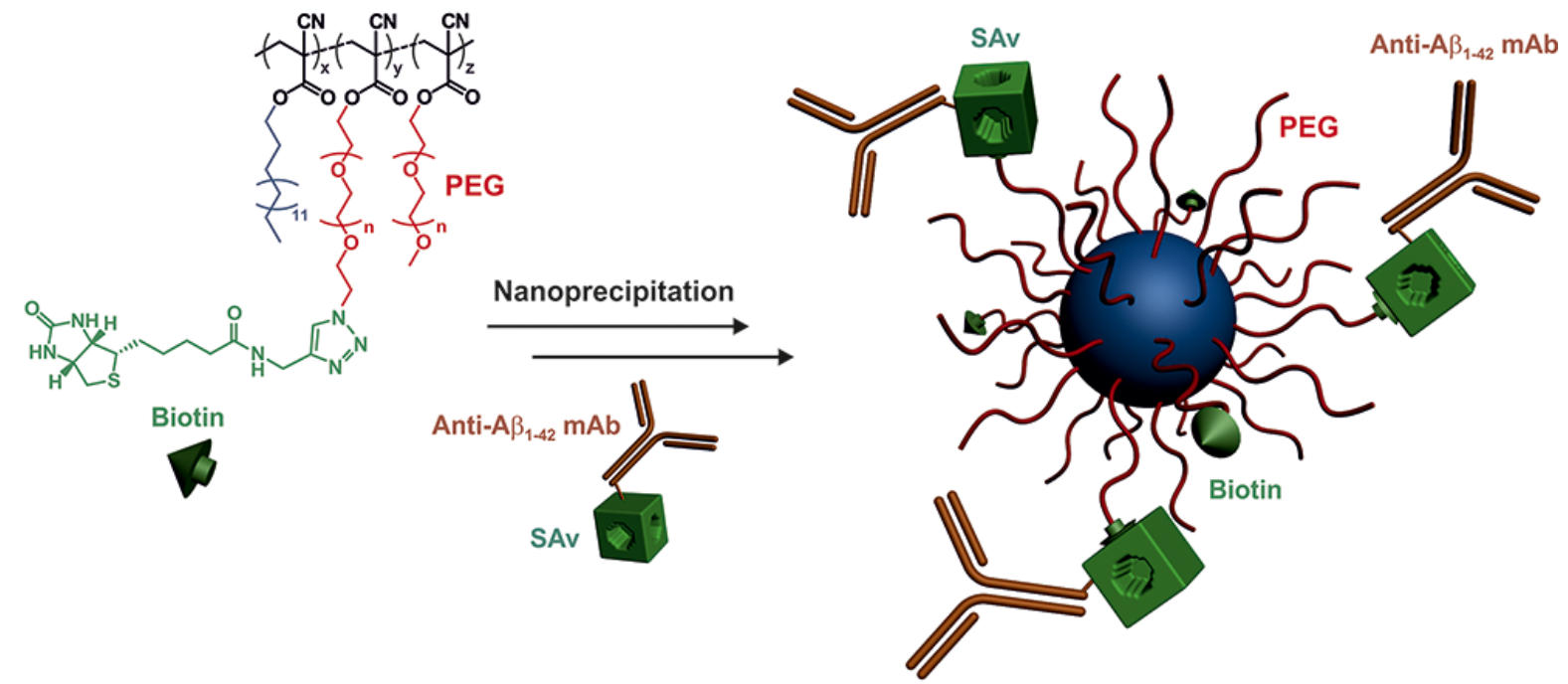

Figure 1. Formation of anti-A $\beta_{1-42}$ monoclonal antibody (mAb)-decorated PEGylated $\mathrm{P}(\mathrm{HDCA}-\mathrm{co}-\mathrm{MePEGCA})$ nanoparticles (anti-A $\left.\beta_{1-42}-\mathrm{NPs}\right)$ from biotinylated P(HDCA-coMePEGCA) copolymer after nanoprecipitation and incubation with streptavidin (SAav)-anti$\mathrm{A} \beta_{1-42} \mathrm{mAb}$.

In this study, we investigated the in vivo pharmacological efficacy of anti-A $\beta_{1-42}-\mathrm{NPs}$ in ADlike transgenic mice and demonstrated that they were able: (i) to bind blood-circulating $A \beta_{1-}$ 42, (ii) to eliminate $A \beta_{1-42}$ species through nanoparticle clearance pathways and (iii) to decrease $A \beta_{1-42}$ brain levels, likely via the sink effect. ${ }^{26}$ Importantly, AD-like transgenic mice treated with anti-A $\beta_{1-42}$-NPs showed a complete correction of the memory defect, together 
with a significant reduction of the $A \beta$ soluble peptide and oligomer brain levels, resulting in a significant increase of the $A \beta$ levels in plasma. This study represents the first example of $A \beta_{1-}$ 42 monoclonal antibody-decorated nanoparticle-based therapy against AD leading to complete correction of the memory defect in an experimental model of AD.

\section{Methods}

\section{Materials}

Poly[(hexadecyl cyanoacrylate-co-rhodamine B cyanoacrylate-co-methoxypoly(ethylene glycol cyanoacrylate)] (P(HDCA-co-RCA-co-MePEGCA)) and poly[methoxypoly(ethylene glycol) cyanoacrylate-co-Biotin-poly(ethylene glycol) cyanoacrylate-co-hexadecyl cyanoacrylate] (MePEGCA-co-Bio-PEGCA-co-HDCA) copolymers were obtained following previously reported procedures. ${ }^{42,}{ }^{43}$ Radio-labeled ${ }^{14} \mathrm{C}-\mathrm{P}(\mathrm{HDCA}-\mathrm{co}$-MePEGCA) copolymer was prepared at the Commissariat à l'Energie Atomique (Saclay, France) according to previously described protocols ${ }^{44}$ and had a specific activity of $5.8 \mathrm{mCi} / \mathrm{mg}$. The Anti-A $\beta_{1-42}$ monoclonal $\mathrm{Ab}$ was prepared by StabVida (Costa da Caparica, Portugal). Dulbecco's phosphate buffer saline (DPBS) without $\mathrm{CaCl}_{2}$ and $\mathrm{MgCl}_{2}$ and $\mathrm{EMB}-2$ medium were purchased from Lonza. Penicillin 10,000 units-streptomycin 10,000 $\mu \mathrm{g} \cdot \mathrm{mL}^{-1}$, trypsin/EDTA and chemically defined lipid concentrate were obtained from Invitrogen, Gibco. Pluronic F68, hydrocortisone, trypsine/EDTA 1X, human basic fibroblast growth factor (bFGF) cell culture tested, glycerol, Tris buffer, sodium dodecyl sulfate (SDS) $(\geq 98.5 \%)$, Triton X100, 3',3",5',5"-tetrabromophenolsulfonphthalein (bromophenol blue), 1,4-dithioerythritol (DTE), acrylamide (40\%), tetramethylethylenediamine (TEMED) ( 99\%), paraformaldehyde (PFA), CHAPS (3-[(3-cholamidopropyl) dimethylammonio]-1-propanesulfonate), thiourea, urea, dithiothreitol (DTT), iodocetamide, glycine, Sypro ruby, agarose, Bradford reagent ammoniun 
persulfate (APS) $(98 \%)$, iminothiolane hydrochloride $(\geq 98 \%)$, streptavidin FITC $(\geq 5$ units/mg protein), $N$-hydroxy-succimide (98\%), Supedex Prep Grade 200 gel and ascorbic acid were purchased from Sigma-Aldrich. Acetone (> 99.95\%) was purchased from Carlo Erba. Soluene-350 and Hionic-Fluor were purchased from Perkin Elmer.

\section{Nanoparticle preparation and characterization}

Fluorescently- and radio-labelled nanoparticles (NPs). The different non-functionalized NPs were prepared following previously described protocols from P(HDCA-co-RCA-coMePEGCA) or ${ }^{14} \mathrm{C}-\mathrm{P}\left(\mathrm{HDCA}-\mathrm{co}\right.$-MePEGCA) copolymers. ${ }^{43}{ }^{44}$ For biotinylated NPs (Bio$\mathrm{NPs}$ ), $9.5 \mathrm{mg}$ of polymer (either $\mathrm{P}\left(\mathrm{HDCA}-c o\right.$-RCA-co-MePEGCA) or ${ }^{14} \mathrm{C}-\mathrm{P}(\mathrm{HDCA}-\mathrm{co}$ MePEGCA)) and $0.5 \mathrm{mg}$ of P(MePEGCA-co-Bio-PEGCA-co-HDCA) were dissolved in acetone $(2 \mathrm{~mL})$ and added dropwise to an aqueous solution $0.5 \%(\mathrm{w} / \mathrm{v})$ of Pluronic F-68 (4 $\mathrm{mL}$ ) under vigorous stirring. Acetone was then evaporated under reduced pressure and the NPs purified by ultracentrifugation $\left(150,000 \mathrm{~g}, 1 \mathrm{~h}, 4{ }^{\circ} \mathrm{C}\right.$, Beckman Coulter). The supernatant was discarded and the pellet was resuspended in the appropriate volume of nanopure water to reach a final concentration of $2.5 \mathrm{mg} \cdot \mathrm{mL}^{-1}$.

Conjugation of streptavidin FITC with anti-A $\beta_{1-42} m A b .2 .5 \mu \mathrm{L}$ of iminothiolane hydrochloride ( $2 \mathrm{mg} . \mathrm{mL}^{-1}$ in borate buffer $0.16 \mathrm{M} \mathrm{pH} 8$ EDTA $0.1 \mathrm{M}$ ) were added to $40 \mu \mathrm{L}$ of streptavidin FITC (2.5 mg.mL $\mathrm{m}^{-1}$ in borate buffer $0.16 \mathrm{M}$ pH 8 EDTA $0.1 \mathrm{M}$ ) and incubated for 30 min under stirring. In parallel $2.5 \mu \mathrm{L}$ of $N$-hydroxysuccimide $\left(1 \mathrm{mg} \cdot \mathrm{mL}^{-1}\right.$ in DMF) were added to $132.5 \mu \mathrm{L}$ of anti-A $\beta$ mAb $\left(0.7 \mathrm{mg} \cdot \mathrm{mL}^{-1}\right.$ in DPBS $)$ and incubated for 90 min under stirring. The two solutions were purified by Amicon Ultra 0.5 $30 \mathrm{KDa}$ filter centrifugation $(18,000 \mathrm{~g}, 5 \mathrm{~min}$, room temperature) and then mixed together. The final volume was adjusted to $100 \mu \mathrm{L}$ with PBS, gently stirred for 120 min and then purified by column filtration using 
Supedex Prep Grade 200 gel. Conjugation was assessed by semi-native polyacrylamide gel electrophoresis (PAGE) (Biorad apparatus) (Figure S1) and the conjugation yield was quantified by spectrofluorimetry (Perkin Elmer Luminescence Spectrometer).

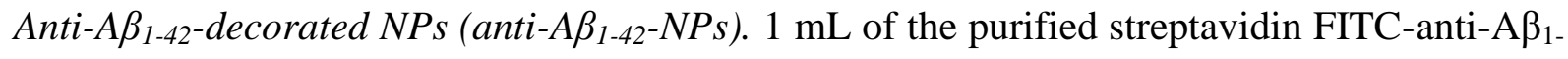
${ }_{42} \mathrm{mAb}$ conjugate was incubated with $1 \mathrm{~mL}$ of Bio-NPs (radiolabeled or not) for $30 \mathrm{~min}$. Anti$\mathrm{A} \beta_{1-42}$-NPs were purified by ultracentrifugation $\left(150,000 \mathrm{~g}, 1 \mathrm{~h}, 4^{\circ} \mathrm{C}\right.$, Beckman Coulter). The supernatant was discarded and the pellet was resuspended in the appropriate volume of nanopure water to obtain a final concentration of $2.5 \mathrm{mg} \cdot \mathrm{mL}^{-1}$. The amount of anti-A $\beta_{1-42}$ $\mathrm{mAb}$ on purified nanoparticles was indirectly evaluated by fluorescence quantification of streptavidin FITC since the streptavidin FITC:mAb molar ratio is 1:1.

Nanoparticle characterization. The average diameter $\left(D_{\mathrm{z}}\right)$ of the nanoparticles was measured by dynamic light scattering (DLS), weighted by intensity, after dilution 1/100 (v/v) in nanopure water with a NanoZS from Malvern $\left(173^{\circ}\right.$ scattering angle, Orsay, France) at $25^{\circ} \mathrm{C}$. The nanoparticle surface charge was determined by $\zeta$-potential measurement at $25{ }^{\circ} \mathrm{C}$ after dilution with $1 \mathrm{mM} \mathrm{NaCl}$ solution applying the Smoluchowski equation and using the same apparatus.

All nanoparticle formulations were stored at $4{ }^{\circ} \mathrm{C}$ in the dark.

In vivo pharmacokinetic and biodistribution of the nanoparticles in normal mice

Animals. 32 NIHS adult male mice between 17 and $27 \mathrm{~g}$ (Harlan Laboratories) were used for this purpose according to European Union (EEC Council Directive 86/609, OJ L 358,1; 12 December 1987) laws and policies and in accordance with the Principles of Laboratory Animal Care and legislation in force in France (Decree No. 2013-118 of February 1, 2013). Animal treatment. Mice were intravenously (IV) injected with radio-labelled anti-A $\beta_{1-42}$-NPs (40 mg/kg). The dose was selected to allow comparisons with previously published results ${ }^{30}$ 
and according to the Standard Operating Procedures and Guidelines in animal experimentation. The animals were sacrificed after different times ( $5 \mathrm{~min}, 1 \mathrm{~h}, 4 \mathrm{~h}$ and $8 \mathrm{~h}$ ) by euthanasia with pentobarbital. The blood was withdrawn and further centrifuged $(4,500 \mathrm{~g}, 15$ min, room temperature, $5810 \mathrm{R}$ centrifuge) to collect the plasma while liver, spleen, kidneys and brain were collected, weighed, and stored at $-80{ }^{\circ} \mathrm{C}$.

Organ analysis. To quantify the amount of NPs, the different tissues were incubated overnight with $\mathrm{H}_{2} \mathrm{O}_{2}$ at $50{ }^{\circ} \mathrm{C}$. Then, Soluene-350 was added and the samples were stored for $1 \mathrm{~h}$ at 50 ${ }^{\circ} \mathrm{C}$. Hionic-Fluor was added and the samples were vortexed for $30 \mathrm{~s}$. After $1 \mathrm{~h}$ at room temperature, the samples were finally analyzed by scintigraphy (Beckman Coulter L5 6500 Multi-Purpose Scintillation Center).

In vivo evaluation of the nanoparticles in AD-like transgenic mice

Animals. 17 Tg2576 14 month-old AD-like transgenic male mice (B6;SJL$\operatorname{Tg}($ APPSWE)2576Kha, Taconic Europe) and 9 wild type (WT) age-matched littermates were

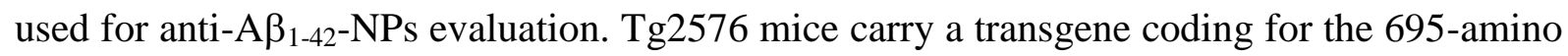
acid isoform of human Alzheimer $\mathrm{A} \beta$ precursor protein carrying the Swedish mutation. All animals were single housed in a specific pathogen free facility in standard mouse cages containing sawdust with food (2018S Harlan diet) and water ad libitum, under conventional laboratory conditions (room temperature: $20 \pm 2{ }^{\circ} \mathrm{C}$; humidity: $60 \%$ ) and a 12/12 h light/dark cycle (7:00 am - 7:00 pm). Drug treatment and behavioral tests were all conducted during the light cycle. No environmental enrichment was used, since it is well known to improve AD mouse pathology. ${ }^{45,46}$ All procedures involving animals and their care were conducted according to European Union (EEC Council Directive 86/609, OJ L 358,1; 12 December 1987) and Italian (D.L. n.116, G.U. suppl. 40, 18 February 1992) laws and policies and in accordance with the United States Department of Agriculture Animal Welfare Act and the 
National Institutes of Health (Bethesda, MA, USA) policy on Human Care and Use of Laboratory Animals. They were reviewed and approved by the Mario Negri Institute Animal Care and Use Committee that includes ad hoc members for ethical issues.

Animal treatment. For novel object recognition tests, all animals (Tg or WT) were IV injected with $100 \mu \mathrm{L}$ (40 mg/kg of polymer) of fluorescently-labelled anti-A $\beta_{1-42}$-NPs $(0.8 \mathrm{mg} / \mathrm{kg}$ of antibody) or PBS as vehicle once every other day for three weeks. To prevent the effect of subjective bias, animals were allocated to treatment by an operator not involved in the study and animal groups were named with numbers. Mice were treated always at the same time of the day (9-11 am), in a specific room inside the animal facility, following a randomized order.

Novel Object Recognition (NOR) test. NOR is a memory test which relies on spontaneous animal behavior without the need of stressful elements such as food or water deprivation or electric foot shock. ${ }^{47}$ In the NOR mice are introduced into an arena containing two identical objects that they can explore freely. Twenty-four hours later mice are reintroduced into the arena, containing two different objects one of which previously presented (familiar) and a new completely different one (novel). At the end of treatment mice were tested in an opensquare grey arena $(40 \times 40 \mathrm{~cm}), 30 \mathrm{~cm}$ high, with the floor divided into 25 squares by black lines, placed in a specific room dedicated to behavioral analysis and separated from the operator's room. The following objects were used: a black plastic cylinder $(4 \times 5 \mathrm{~cm})$, a glass vial with a white cup $(3 \times 6 \mathrm{~cm})$ and a metal cube $(3 \times 5 \mathrm{~cm})$. The task started with a habituation trial during which the animals were placed in the empty arena for 5 minutes and their movements recorded as the number of line-crossings, which provide an indication of both WT and Tg mice motor activity. The next day, mice were again placed in the same arena containing two identical objects (familiarization phase). Exploration was recorded in a 10minute trial by an investigator blinded to the genotype and treatment. Sniffing, touching and 
stretching the head toward the object at a distance of not more than $2 \mathrm{~cm}$ were scored as object investigation. Twenty-four hours later (test phase) mice were again placed in the arena containing two objects: one of the objects presented during the familiarization phase (familiar object, FAM), and a new, different one (novel object, NOV), and the time spent exploring the two objects was recorded for $10 \mathrm{~min}$. Mice were tested following a pre-defined scheme (5 mice for each treatment group and the remaining mice by following the same scheme) so to precisely maintain the $24 \mathrm{~h}$ of re-test for each mouse. Results were expressed as $\%$ time of investigation on objects/10 min or as discrimination index (DI), that is: (seconds spent on novel - seconds spent on familiar)/(total time spent on objects). Animals with no memory impairment spent longer time investigating the novel object, giving a higher discrimination index.

Brain immunohistochemistry. $\mathrm{Tg} 2576$ plaque deposition was examined using the 6E10 monoclonal anti-A $\beta$ antibody (Covance, CA) following a previously reported procedure. ${ }^{30}$ Brain coronal cryostat sections ( $30 \mu \mathrm{m} ; 3$ slice/mouse) were incubated for $1 \mathrm{~h}$ at RT with blocking solutions (10\% normal goat serum in PBS) then overnight at $4{ }^{\circ} \mathrm{C}$ with the primary antibodies (1:500). After incubation with the anti-mouse biotinylated secondary antibody (1:200; 1h RT, Vector Laboratories) immunostaining was developed using the avidin-biotin kit (Vector Laboratories) and diaminobenzidine (Sigma, Italy). Tissue analysis and image acquisition were done using an Olympus image analyzer and the Cell-R software.

Statistical analysis. Data were expressed as mean \pm standard error of the mean (SEM). For the NOR test, data were analysed by a one-way analysis of variance (ANOVA). In the presence of a significant effect of treatment the Tukey's post-hoc test was applied. A $p$-value $<0.05$ was considered significant. 
Brain homogenate preparation and quantification of $A \beta_{1-42}$ and $A \beta_{1-40}$. Brain homogenates were prepared as reported elsewhere ${ }^{30,48}$ with some modifications. Frozen mouse brain hemispheres were thawed for $\sim 30 \mathrm{~s}$, weighted and homogenized $(1: 2 \mathrm{w} / \mathrm{v})$ in ice-cold extraction buffer containing 50 mM TRIS-HCl (pH 7.4), $150 \mathrm{mM} \mathrm{NaCl}, 50 \mathrm{mM}$ EDTA, $1 \%$ Triton X-100 (TX) and 2\% protease inhibitor cocktail (Roche) with a manual tissue homogenizer (Eppendorf, Italy). Brain homogenates were centrifuged at $21000 \mathrm{~g}, 4^{\circ} \mathrm{C}$ for 30 min and the supernatants, referred to as the Triton-soluble fractions (soluble A $\beta$ ), were removed with care taken not to disturb the pellet and stored at $-80{ }^{\circ} \mathrm{C}$ until $\mathrm{A} \beta$ dosage. The pellets remaining after the TX extract were re-suspended in $70 \%$ formic acid (FA) $(1: 10 \mathrm{w} / \mathrm{v})$, homogenized and centrifuged at $100.000 \mathrm{~g}, 4{ }^{\circ} \mathrm{C}, 1 \mathrm{~h}$ in Beckman TL-100 ultracentrifuge. The resulting FA-extracted supernatants, referred to as FA-soluble fraction (insoluble A $\beta$ ) were neutralized with $1 \mathrm{M}$ TRIS buffer $(\mathrm{pH} 11)$ and stored at $-80^{\circ} \mathrm{C}$ until $\mathrm{A} \beta$ dosage.

Levels of $A \beta_{1-40}$ and $A \beta_{1-42}$ in each fraction were quantified by sandwich enzymelinked immunosorbent assay (ELISA kit, IBL, Germany) following the manufacturer's instruction. The total protein content in each fraction was quantified by bicinchoninic acid assay (Sigma-Aldrich, Milano, Italy). All samples were analyzed at least in triplicate.

Western blot analysis of brain A $\beta$ assemblies. Western blot analysis of $\mathrm{A} \beta$ oligomers was performed as reported elsewhere ${ }^{30,49}$ with some modifications. Aliquots of TX-soluble A $\beta$ fractions containing $50 \mu \mathrm{g}$ of total proteins (quantified by bicinchoninic acid assay, SigmaAldrich, Milano, Italy) were combined with NuPAGE® Sample Buffer, heated at $70{ }^{\circ} \mathrm{C}$ for 10 min before electrophoresing on NuPAGE Novex 4-12\% Bis-tris gels at $200 \mathrm{~V}$ for $35 \mathrm{~min}$ (Invitrogen corporation, Milano, Italy) and electro-transferred onto nitrocellulose membrane (GE Healthcare). The membrane was blocked in 5\% skim milk in TRIS buffered salinetween-20 (TBS-T) (10 mM Tris-HCl, $150 \mathrm{mM} \mathrm{NaCl,} \mathrm{0.1 \%} \mathrm{Tween-20,} \mathrm{pH} 8.0)$ for $30 \mathrm{~min}$ at $37{ }^{\circ} \mathrm{C}$, incubated with the $6 \mathrm{E} 10$ anti-A $\beta$ antibody (1:1000 dilution) in blocking buffer 
overnight at $4^{\circ} \mathrm{C}$. Blot was rinsed in TBS-T and then incubated with secondary antibody (1.5 h, RT, 1:20 000 dilution), followed by further rinsing. Bands were visualized with enhanced chemiluminescence (ECL) Reagent (Amersham, USA) and then imaged using ImageQuant LAS4000 (GE Healthcare). Molecular weight of A $\beta$ bands was determined by comparison to the SeeBlue®Plus2 Pre-stained Standard (Invitrogen corporation, Milano, Italy). The content of soluble $\mathrm{A} \beta$ assemblies was quantified by measuring the intensity of the chemiluminescent bands using ImageJ Software.

Quantification of $A \beta$ in plasma. After sacrifice, mice blood was collected from the hearth and processed for plasma separation. Levels of $A \beta_{1-40}$ and $A \beta_{1-42}$ in plasma were quantified by sandwich enzyme-linked immunosorbent assay (Wako Chemicals GmbH, Germany) following the manufacture's instruction. All samples were analyzed at least in triplicate.

\section{Results}

Preparation of anti-A $\beta_{1-42}-N P s$

Nanoparticles with high affinity for the $A \beta_{1-42}$ peptide were produced by coupling an anti$\mathrm{A} \beta_{1-42}$ monoclonal antibody at the PEG chain ends of P(HDCA-co-MePEGCA) nanoparticles via Bio-SAv ligation. $^{42}$ In particular, the P(MePEGCA-co-Bio-PEGCA-co-HDCA) copolymer was nanoprecipitated in water and the resulting Bio-NPs were incubated with a streptavidin FITC-anti-A $\beta_{1-42}$ mAb conjugate to yield anti-A $\beta_{1-42}$-NPs (see Methods section). The nanoparticles presented an average diameter of $125 \mathrm{~nm}$ with rather narrow particle size distributions $(\mathrm{PDI}=0.1-0.2)$ and negative $\zeta$-potentials $(-20$ to $-30 \mathrm{mV})$. These characteristics did not significantly change during the duration of the experiments, thus showing great colloidal stability. To enable accurate tracing during biological evaluations, radio-labelled anti-A $\beta_{1-42}$-NPs were also prepared, simply by blending a small amount of ${ }^{14} \mathrm{C}-\mathrm{P}(\mathrm{HDCA}-\mathrm{co}$ - 
MePEGCA) copolymer with P(MePEGCA-co-Bio-PEGCA-co-HDCA) prior their conanoprecipitation to give ${ }^{14} \mathrm{C}$ anti-A $\beta_{1-42}$-NPs (average diameter $=182 \mathrm{~nm}, \mathrm{PDI}=0.22$ ).

\section{Pharmacokinetics and biodistribution of anti-A $\beta_{1-42}-N P s$}

To evaluate their biodistribution profile, wild type (WT) mice were intravenously injected with ${ }^{14} \mathrm{C}$ anti-A $\beta_{1-42}$-NPs $(40 \mathrm{mg} / \mathrm{kg})$ and the radioactivity was quantified at increasing time point in blood, liver, spleen, kidneys and brain (Figure 2). The nanoparticles demonstrated long blood circulation half-life because of their PEG coating (more than $19 \%$ of the injected dose/g of organ after $8 \mathrm{~h}$ ) with preferential accumulation in liver (plateauing at $13 \%$ after $1 \mathrm{~h}$ ), spleen (constantly more than 50\% after $1 \mathrm{~h}$ ) and, to a lesser extent, in kidneys (4-7\% at $8 \mathrm{~h}$ ). Importantly, although liver accumulation was previously observed for non-functionalized $\mathrm{P}\left(\mathrm{HDCA}-\mathrm{co}\right.$-PEGCA) NPs ${ }^{38}$ the high amount accumulating in the spleen seems peculiar for ${ }^{14} \mathrm{C}$ anti-A $\beta_{1-42}$-NPs. The spleen has a blood filtration system presenting tight reticular mesh of $200 \mathrm{~nm}$ in width. ${ }^{50}$ Consequently, ${ }^{14} \mathrm{C}$ anti-A $\beta_{1-42}$-NPs could be preferentially taken up by the spleen due to their average bigger size compared to the non-functionalized NPs, as previously described for other NPs. ${ }^{51} \mathrm{~A}$ low, but detectable amount of ${ }^{14} \mathrm{C}$ anti-A $\beta_{1-42}$-NPs was also found in the brain $(\sim 0.5 \%)$, confirming the ability of these NPs to diffuse into the brain tissue to a certain extent. ${ }^{52,53}$ 


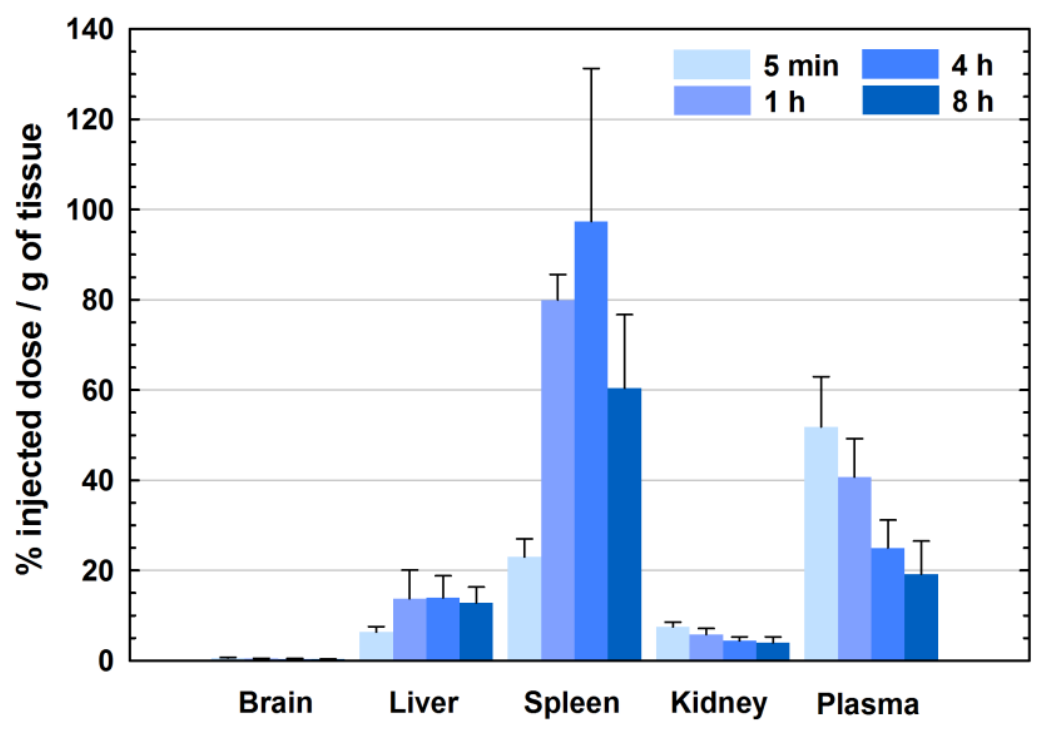

Figure 2. Biodistribution of radio-labelled anti-A $\beta_{1-42}-\mathrm{NPs}$ in wild type mice. Quantification of ${ }^{14} \mathrm{C}$ anti-A $\beta_{1-42}$-NPs in the main organs at $5 \mathrm{~min}, 1 \mathrm{~h}, 4 \mathrm{~h}$ and $8 \mathrm{~h}$ after intravenous injection of $40 \mathrm{mg} / \mathrm{kg}$ in wild type mice $(\mathrm{n}=4)$.

\section{Novel object recognition (NOR) test}

To evaluate the effect of anti-A $\beta_{1-42}$-NPs on memory recovery, $\mathrm{AD}$-like transgenic mice $(\mathrm{Tg}$ 2576) and WT mice were intravenously injected (3 days/week for 3 weeks) with $100 \mu \mathrm{L}$ of PBS buffer (untreated) or anti-A $\beta_{1-42}$-NPs $(40 \mathrm{mg} / \mathrm{kg}$ ), following by their evaluation by a NOR test. NOR is a memory test that relies on spontaneous animal behaviour and has become a widely used model for investigating memory alterations. ${ }^{47}$ Figure 3 shows that Tg2576 animals receiving PBS were unable to discriminate between familiar and novel objects (\% investigation FAM: $52.8 \pm 3.3$, NOV: $47.2 \pm 3.3$; DI:-0.1), thus displaying a significant memory impairment compared to WT mice (\% investigation FAM: $36.3 \pm 3.7$, NOV: $63.7 \pm$ 3.7; DI: 0.27). On the other hand, Tg2576 mice treated with anti-A $\beta_{1-42}$-NPs significantly recovered their long-term recognition memory, near to normal (\% investigation FAM: $36.5 \pm$ 2.4, NOV: $63.5 \pm 2.4$; DI:0.26). Importantly, neither transgene nor treatment affected motor behaviour of mice measured as total number of movements inside the empty arena during the 
habituation trial of the NOR test (one-way ANOVA: $\mathrm{F}_{2,23}=1.2 ; \mathrm{P}=0.3$ ). Altogether, these data demonstrated that an acute treatment with anti-A $\beta_{1-42}-\mathrm{NPs}(40 \mathrm{mg} / \mathrm{kg}$ of polymer) completely restored memory deficit in Tg2576 mice. Further experiments would be required to investigate the effect of lower doses and/or shorter treatments to refine the therapeutic dose.
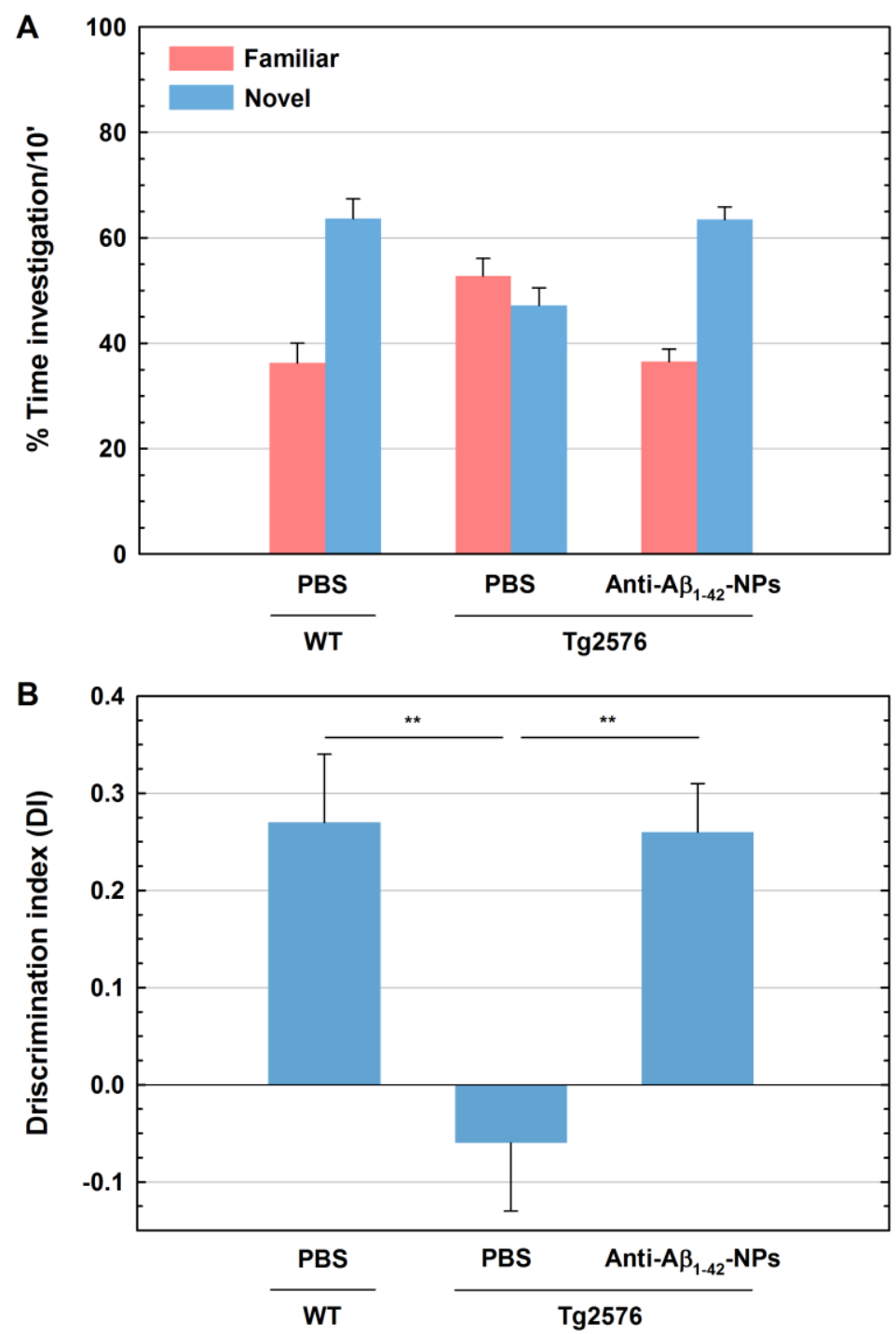

Figure 3. Impact of nanoparticle-based treatments on Tg2576 mouse memory. Memory evaluation after PBS or anti-A $\beta_{1-42}$-NPs $(40 \mathrm{mg} / \mathrm{kg})$ administration 3 injections/week for 3 weeks: (A) time \% investigation on the novel vs. the familiar object of WT mice $(n=9)$ and $\operatorname{Tg} 2576$ mice $(n=9)$ at the end of treatment; (B) quantification of discrimination index. Histograms are mean \pm SEM. One-way ANOVA found a significant effect of treatment: $F_{2,23}$ $=8.0, p=0.002 . * * p<0.01$ by Tukey's post-hoc test. 


\section{Brain and plasma levels of $A \beta$}

To elucidate the mechanisms governing the observed in vivo efficacy of anti-A $\beta_{1-42}-\mathrm{NPs}$, dosage of $\mathrm{A} \beta$ species in brain and plasma of mice was performed. After treatment with anti$\mathrm{A} \beta_{1-42}$-NPs, mice were sacrificed and brain hemispheres were analyzed for the soluble and insoluble $\mathrm{A} \beta$ content by ELISA. The results showed that the treatment did not induce any significant reduction of insoluble brain $A \beta$ burden (Figure $4 a$ ), whereas a significant reduction $(-20 \%)$ of the Triton-soluble $A \beta_{1-40}$ and $A \beta_{1-42}$ levels $(15.40 \pm 1.72$ and $98.59 \pm 9.13$ pmols of $\mathrm{A} \beta / \mathrm{mg}$ total proteins, respectively) was detected by comparison with the soluble $A \beta_{1-40}$ and $\mathrm{A} \beta_{1-42}$ levels in mice treated with PBS $(21.73 \pm 3.38$ and $114.07 \pm 10.11$ pmols of $\mathrm{A} \beta / \mathrm{mg}$ of total proteins, respectively) (Figure 4b). 

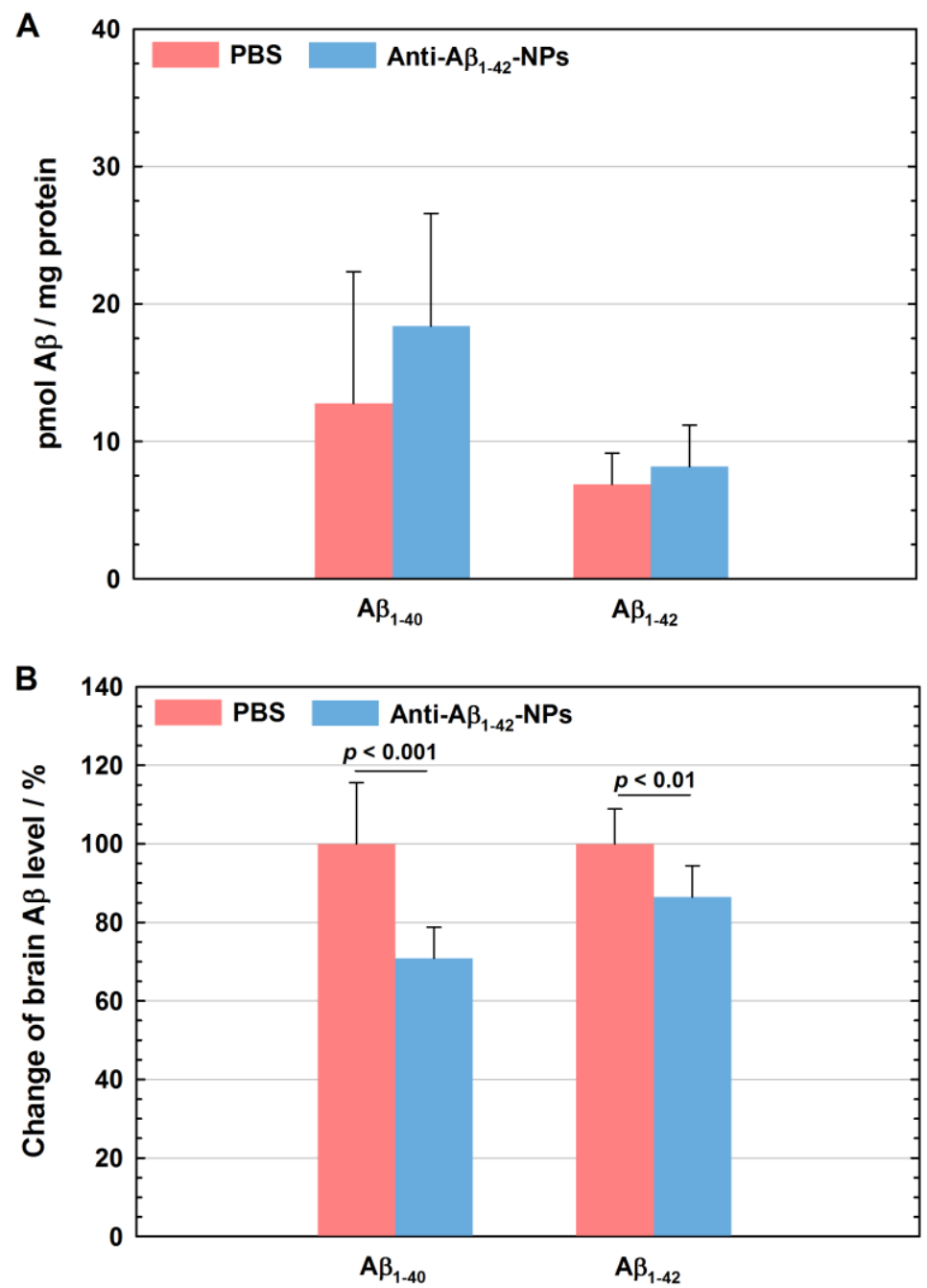

Figure 4. Soluble and insoluble $A \beta$ levels in the brain of Tg2576 mice after treatment with anti-A $\boldsymbol{\beta}_{1-42}$ NPs. (A) Insoluble $A \beta_{1-40}$ and $A \beta_{1-42}$ levels in the brain of Tg2576 mice after 3 weeks' treatment with anti-A $\beta_{1-42}-\mathrm{NPs}$ or PBS. Data (mean \pm SD) are expressed as pmol of $\mathrm{A} \beta / \mathrm{mg}$ of total proteins. (B) Triton-soluble $\mathrm{A} \beta$ (i.e., oligomers) levels in the brain of $\mathrm{Tg} 2576$ mice are reduced after treatment with anti-A $\beta_{1-42}$-NPs. Triton-soluble $A \beta$ levels in the brain of Tg2576 mice after 3 weeks' treatment with anti- A $\beta_{1-42}-$ NPs or PBS. Data (mean \pm SD) are expressed as a $\%$ of change of $A \beta$ levels. $p$ values were calculated by Student's t test.

In parallel, an aliquot of the Triton-soluble $A \beta$ fraction was submitted to SDS-PAGE/WB. Representative western blot of brain soluble $A \beta$ probed with $6 \mathrm{E} 10$ anti-A $\beta$ mAb and visualized by ECL (Figure 5a). An estimation of the A $\beta$ assemblies sorted by molecular weight (MW) was performed by quantifying the intensity of the chemiluminescent bands 
using the ImageJ Software. It was observed that treatment with anti-A $\beta_{1-42}$-NPs significantly reduced the amount of $A \beta$ oligomers for all analyzed MWs with the highest effect observed for oligomers $\leq 49 \mathrm{kDa}$ (Figure $5 \mathrm{~b}$ ).
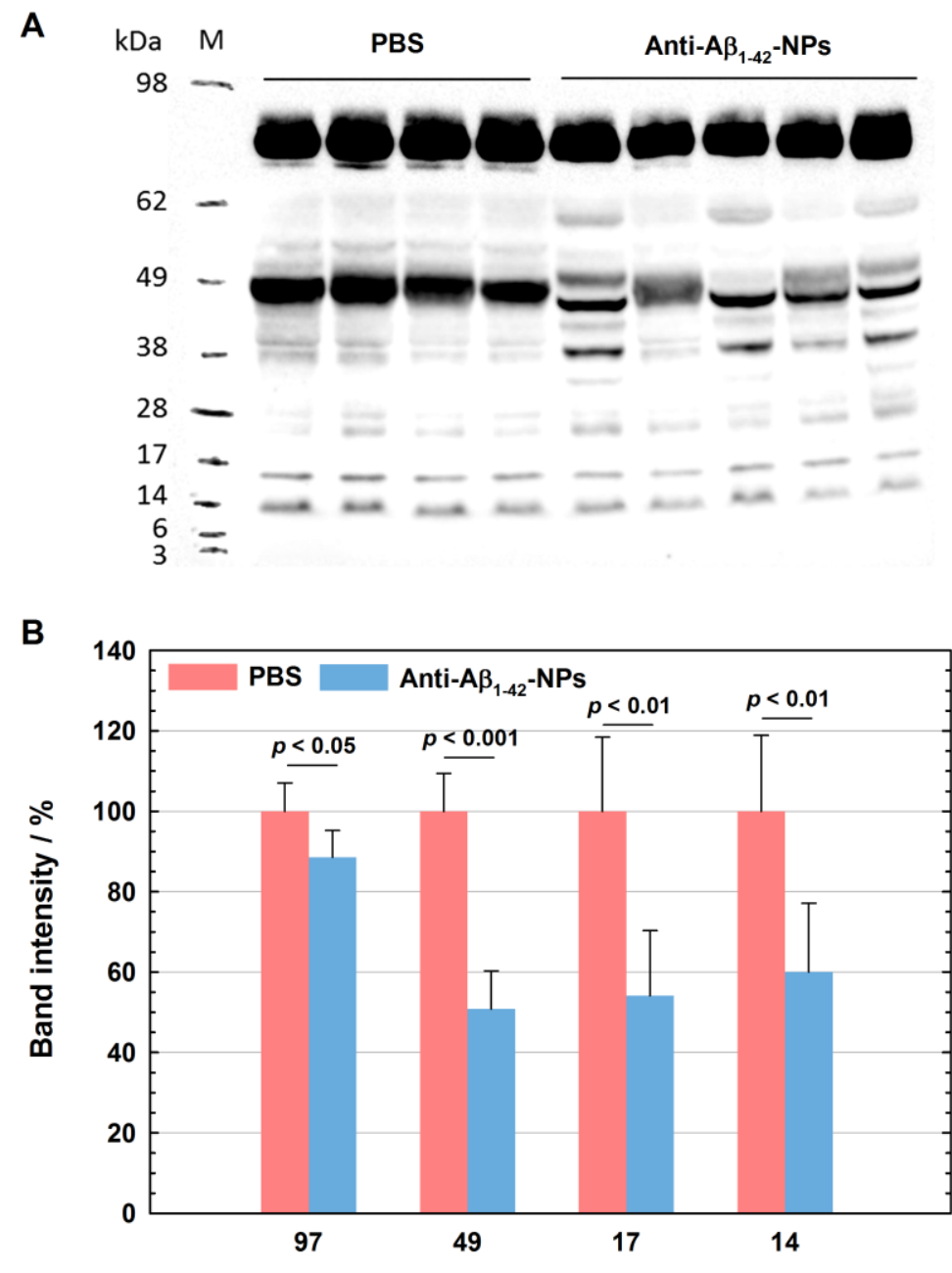

Molecular weight of $\mathrm{A} \beta$ assemblies / $\mathrm{kDa}$

Figure 5. Amount of $A \beta$ oligomers of different $M W$ in the brain of Tg2576 mice after treatment with anti-A $\boldsymbol{\beta}_{1-42}$-NPs. (A) Representative WB of $A \beta$ oligomers probed with $6 \mathrm{E} 10$ anti-A $\beta_{1-42} \mathrm{mAb}$ and visualized by ECL. (B) Estimation of $\mathrm{A} \beta$ assemblies sorted by MW present in the brain of $\mathrm{Tg} 2576$ treated with PBS taken as reference or with anti-A $\beta_{1-42}$-NPs obtained by quantifying the intensity of the chemiluminescent bands using the ImageJ Software. Data (mean $\pm \mathrm{SD}$ of triplicate experiments) are expressed as $\%$ of change of $\mathrm{A} \beta$ levels. $p$ values were calculated by Student's t test. 
After treatment of $\mathrm{Tg} 2576$ mice with anti-A $\beta_{1-42}-\mathrm{NPs}$ or PBS, blood was also collected from the heart and processed for plasma separation. Total levels of $A \beta_{1-40}$ and $A \beta_{1-42}$ were quantified by ELISA assay. Figure 6 showed that the 3 weeks' treatment with anti-A $\beta_{1-42}$-NPs induced a significant increase $(+20 \%)$ of the $A \beta$ levels in plasma compared to the mice treated with PBS.

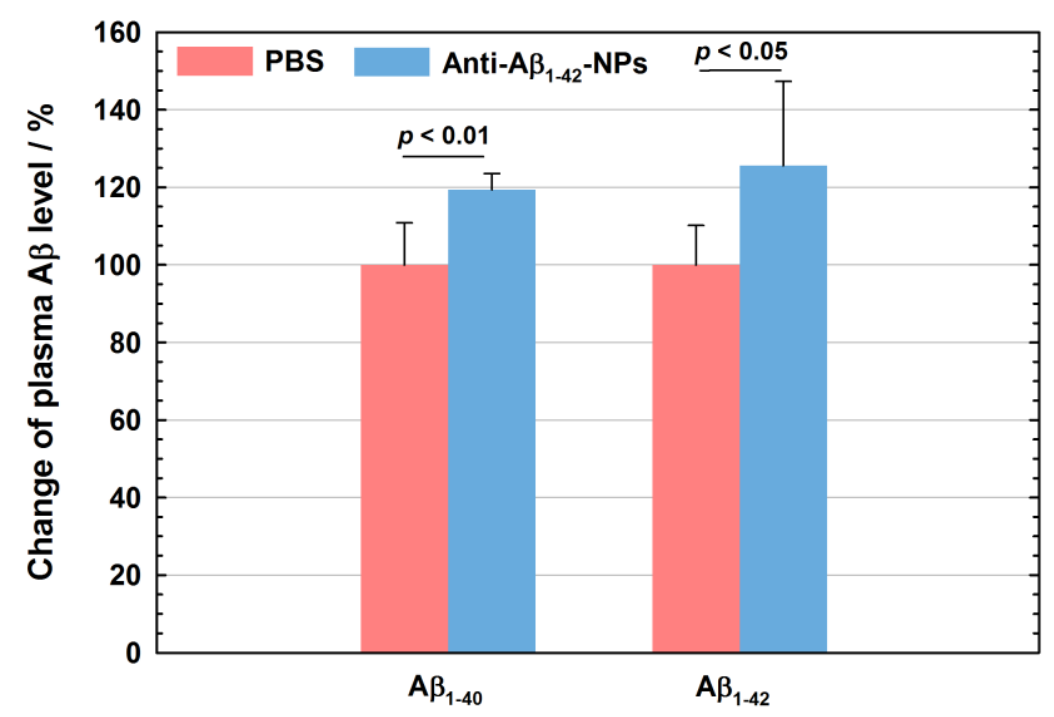

Figure 6. A $\beta$ levels in plasma of Tg2576 mice after treatment with anti-A $\beta_{1-42}-\mathrm{NPs}$. Tg2576 mice treated with PBS or with anti-A $\beta_{1-42}$-NPs. Data (mean \pm SD) are expressed as a $\%$ of change of $A \beta$ levels. $p$ values were calculated by Student's t test.

\section{Discussion}

Altogether, these data support the hypothesis of a mechanism explaining the therapeutic efficacy of anti-A $\beta_{1-42}$-NPs to reduce soluble forms of $A \beta$ and rescue memory in AD mice. The therapeutic effect observed in vivo could be mainly driven by the higher concentration of anti-A $\beta_{1-42}$-NPs detected in the blood than in the brain, likely through the sink effect. ${ }^{26}$ Nevertheless, we do not exclude the contribution of the NPs found in the brain since low brain concentrations of nanomedicines (e.g., 0.1-0.2\%) have shown significant improvement of 
neurological and histological phenotype in neurodegenerative disease animal models. ${ }^{54}$ After intravenous injection of anti-A $\beta_{1-42}-\mathrm{NPs}$, their surface would be covered by blood-circulating $\mathrm{A} \beta$, followed by clearance of the resulting $\mathrm{A} \beta$-coated NPs by classic nanoparticle elimination pathways such as phagocytic uptake and hepatic filtration or through kidney excretion. ${ }^{55}$ This would result in a global reduction of blood-circulating $A \beta$, leading to a drastic decrease of its aggregation kinetics. Moreover, the peripheral elimination of $\mathrm{A} \beta$ peptides would shift the blood-BBB equilibrium of the peptide leading to $A \beta$ translocation from the brain to the peripheral circulation mediated by receptors like LRP1 or P-gp, in agreement with the socalled "sink effect".

These results demonstrated the beneficial effect of nanoparticles decorated by an A $\beta$ targeted antibody on memory recovery in AD-like transgenic animals and supported the great potential of anti-A $\beta$ oriented research. They also represent a promising step towards antibodydecorated nanoparticle-based therapy against $\mathrm{AD}$ and all the results that were collected in this study were in good agreement with the "sink effect" hypothesis. Also, not only the conception of such nanocarriers is rather simple, as it only relied on surface functionalization of PEGylated nanoparticles by an anti- $\mathrm{A} \beta_{1-42}$ monoclonal antibody, but the therapeutic mechanism (peripheral action in the blood following intravenous injection) also avoids the design of complex multifunctional nanoobjects with, for example, specific ligands to cross the BBB.

\section{Acknowledgements}

The research leading to these results has received funding from the European Community's Seventh Framework Program (FP7/2007-2013) under agreement $n^{\circ} 212043$. The CNRS and the French Ministry of Research are also warmly acknowledged for financial support. Hélène Chacun, Juliette Vergnaud, Gillian Barratt and Céline Boursier (IFR141-IPSIT) are 
acknowledged for their help. Carlo Ferrarese (Department of Neurology, San Gerardo Hospital, Monza), Elisa Conti (Laboratory Neurobiology, School of Medicine, University of Milano-Bicocca, Monza, Italy) are acknowledged for providing blood samples from human AD patients and healthy controls. Frederic Taran and Dominique Georgin (CEA, France) are also warmly acknowledged for the synthesis of ${ }^{14} \mathrm{C}$ polymers.

\section{Supporting Information}

Supplementary Figure S1.

\section{References}

1 Anand, R., K. D. Gill and A. A. Mahdi. Therapeutics of Alzheimer's disease: Past, present and future. Neuropharmacol. 2014;76, Part A:27-50

2 Kumar, A., A. Singh and Ekavali. A review on Alzheimer's disease pathophysiology and its management: an update. Pharmacol Rep. 2015;67:195-203

3 Prince, M. J., 2015. World Alzheimer Report 2015: The Global Impact of Dementia: an Analysis of Prevalence, Incidence, Cost and Trends.

4 Stelzmann, R. A., H. Norman Schnitzlein and F. Reed Murtagh. An english translation of alzheimer's 1907 paper, "über eine eigenartige erkankung der hirnrinde". Clin Anat. 1995;8:429-31

5 Karran, E., M. Mercken and B. De Strooper. The amyloid cascade hypothesis for Alzheimer's disease: an appraisal for the development of therapeutics. Nat Rev Drug Discov. 2011;10:698-712

6 Glenner, G. G. and C. W. Wong. Alzheimer's disease: initial report of the purification and characterization of a novel cerebrovascular amyloid protein. Biochem Biophys Res Commun. 1984;120:885-90

7 Goldgaber, D., M. I. Lerman, W. O. McBride, U. Saffiotti and D. C. Gajdusek. Isolation, characterization, and chromosomal localization of human brain cDNA clones coding for the precursor of the amyloid of brain in Alzheimer's disease, Down's syndrome and aging. J Neural Transm Suppl. 1987;24:23-8

8 van der Kant, R. and Lawrence S. B. Goldstein. Cellular Functions of the Amyloid Precursor Protein from Development to Dementia. Dev Cell. 2015;32:502-15

9 Muresan, V. and Z. Ladescu Muresan. Amyloid- $\beta$ precursor protein: Multiple fragments, numerous transport routes and mechanisms. Exp Cell Res. 2015;334:45-53

10 Hardy, J. and D. J. Selkoe. The amyloid hypothesis of Alzheimer's disease: progress and problems on the road to therapeutics. Science. 2002;297:353-6 
11 Allaman, I., M. Gavillet, M. Belanger, T. Laroche, D. Viertl, H. A. Lashuel, et al. Amyloid-beta aggregates cause alterations of astrocytic metabolic phenotype: impact on neuronal viability. J Neurosci. 2010;30:3326-38

12 Garcia-Matas, S., N. de Vera, A. O. Aznar, J. M. Marimon, A. Adell, A. M. Planas, et al. In Vitro and In Vivo Activation of Astrocytes by Amyloid-beta is Potentiated by Pro-Oxidant Agents. J. Alzheimer's Dis. 2010;20:229-45

13 Cizas, P., R. Budvytyte, R. Morkuniene, R. Moldovan, M. Broccio, M. Lösche, et al. Size-dependent neurotoxicity of $\beta$-amyloid oligomers. Arch Biochem Biophys. 2010;496:84-92

14 Maezawa, I., P. I. Zimin, H. Wulff and L. W. Jin. Amyloid-beta protein oligomer at low nanomolar concentrations activates microglia and induces microglial neurotoxicity. $J$ Biol Chem. 2011;286:3693-706

15 Pitschke, M., R. Prior, M. Haupt and D. Riesner. Detection of single amyloid [beta]protein aggregates in the cerebrospinal fluid of Alzheimer's patients by fluorescence correlation spectroscopy. Nat Med. 1998;4:832-4

16 Mastrangelo, I. A., M. Ahmed, T. Sato, W. Liu, C. Wang, P. Hough, et al. Highresolution Atomic Force Microscopy of Soluble A 342 Oligomers. J Mol Biol. 2006;358:106-19

17 Eckman, C. B. and E. A. Eckman. An update on the amyloid hypothesis. Neurol Clin. 2007;25:669-82, vi

18 Brambilla, D., B. Le Droumaguet, J. Nicolas, S. H. Hashemi, L.-P. Wu, S. M. Moghimi, et al. Nanotechnologies for Alzheimer's disease: therapy, diagnosis and safety issues. Nanomedicine: NBM. 2011;7:521-40

19 Barone, E., F. Di Domenico and D. A. Butterfield. Statins more than cholesterol lowering agents in Alzheimer disease: Their pleiotropic functions as potential therapeutic targets. Biochem Pharmacol. 2014;88:605-16

20 Fernandez, P. L., G. B. Britton and K. S. Rao. Potential immunotargets for Alzheimer's disease treatment strategies. J Alzheimers Dis. 2013;33:297-312

21 Eskici, G. and P. H. Axelsen. Copper and Oxidative Stress in the Pathogenesis of Alzheimer's Disease. Biochemistry. 2012;51:6289-311

22 Hellweg, R., Y. Wirth, W. Janetzky and S. Hartmann. Efficacy of memantine in delaying clinical worsening in Alzheimer's disease (AD): responder analyses of nine clinical trials with patients with moderate to severe AD. Int J Geriatr Psychiatry. 2012;27:651-6

23 Hansen, R. A., G. Gartlehner, A. P. Webb, L. C. Morgan, C. G. Moore and D. E. Jonas. Efficacy and safety of donepezil, galantamine, and rivastigmine for the treatment of Alzheimer's disease: a systematic review and meta-analysis. Clin Interv Aging. 2008;3:211-25

24 Querfurth, H. W. and F. M. LaFerla. Alzheimer's Disease. N Engl J Med. 2010;362:32944

25 Allgaier, M. and C. Allgaier. An update on drug treatment options of Alzheimer's disease. Front Biosci. 2014;19:1345-54

26 Toyn, J. What lessons can be learned from failed Alzheimer's disease trials? Expert Rev Clin Pharm. 2015;8:267-9 
27 Sanhai, W. R., J. H. Sakamoto, R. Canady and M. Ferrari. Seven challenges for nanomedicine. Nat Nanotechnol. 2008;3:242-4

28 Farokhzad, O. C. and R. Langer. Impact of Nanotechnology on Drug Delivery. ACS Nano. 2009;3:16-20

29 Re, F., I. Cambianica, S. Sesana, E. Salvati, A. Cagnotto, M. Salmona, et al. Functionalization with ApoE-derived peptides enhances the interaction with brain capillary endothelial cells of nanoliposomes binding amyloid-beta peptide. J Biotechnol. 2011;156:341-6

30 Balducci, C., S. Mancini, S. Minniti, P. La Vitola, M. Zotti, G. Sancini, et al. Multifunctional Liposomes Reduce Brain $\beta$-Amyloid Burden and Ameliorate Memory Impairment in Alzheimer's Disease Mouse Models. J Neurosc. 2014;34:14022-31

31 Song, Q., M. Huang, L. Yao, X. Wang, X. Gu, J. Chen, et al. Lipoprotein-Based Nanoparticles Rescue the Memory Loss of Mice with Alzheimer's Disease by Accelerating the Clearance of Amyloid-Beta. ACS Nano. 2014;8:2345-59

32 Ordóñez-Gutiérrez, L., A. Posado-Fernández, D. Ahmadvand, B. Lettiero, L. Wu, M. Antón, et al. ImmunoPEGliposome-mediated reduction of blood and brain amyloid levels in a mouse model of Alzheimer's disease is restricted to aged animals. Biomaterials. 2017;112:141-52

33 Fay, F. and C. J. Scott. Antibody-targeted nanoparticles for cancer therapy. Immunotherapy. 2011;3:381-94

34 Nicolas, J., S. Mura, D. Brambilla, N. Mackiewicz and P. Couvreur. Design and Functionalization Strategies for Biodegradable/Biocompatible Polymer-Based Nanoparticles Applied in Targeted Drug Delivery. Chem Soc Rev. 2013;42:1147-235

35 de Verdiere, A. C., C. Dubernet, F. Nemati, E. Soma, M. Appel, J. Ferte, et al. Reversion of multidrug resistance with polyalkylcyanoacrylate nanoparticles: towards a mechanism of action. Br J Cancer. 1997;76:198-205

36 Balland, O., H. Pinto-Alphandary, S. Pecquet, A. Andremont and P. Couvreur. The uptake of ampicillin-loaded nanoparticles by murine macrophages infected with Salmonella typhimurium. J Antimicrob Chemother. 1994;33:509-22

37 Nicolas, J. and P. Couvreur. Synthesis of poly(alkyl cyanoacrylate)-based colloidal nanomedicines. Wiley Interdiscip Rev Nanomed Nanobiotechnol. 2009;1:111-27

38 Vauthier, C., C. Dubernet, E. Fattal, H. Pinto-Alphandary and P. Couvreur. Poly(alkylcyanoacrylates) as biodegradable materials for biomedical applications. $A d v$ Drug Delivery Rev. 2003;55:519-48

39 Lenaerts, V., P. Couvreur, D. Christiaensleyh, E. Joiris, M. Roland, B. Rollman, et al. Degradation of poly(isobutyl cyanoacrylate) nanoparticles. Biomaterials. 1984;5:65-8

40 Kattan, J., J. P. Droz, P. Couvreur, J. P. Marino, A. Boutan-Laroze, P. Rougier, et al. Phase I clinical trial and pharmacokinetic evaluation of doxorubicin carried by polyisohexylcyanoacrylate nanoparticles. Invest New Drugs. 1992;10:191-9

41 Brambilla, D., R. Verpillot, B. Le Droumaguet, J. Nicolas, M. Taverna, J. Kóňa, et al. PEGylated Nanoparticles Bind to and Alter Amyloid-Beta Peptide Conformation: Toward Engineering of Functional Nanomedicines for Alzheimer's Disease. ACS Nano. 2012;6:5897-908 
42 Le Droumaguet, B., J. Nicolas, D. Brambilla, S. Mura, A. Maksimenko, L. De Kimpe, et al. Versatile and Efficient Targeting from a Single Nanoparticulate Platform: Application to Cancer and Alzheimer's Disease. ACS Nano. 2012;6:5866-79

43 Brambilla, D., J. Nicolas, B. Le Droumaguet, K. Andrieux, V. Marsaud, P.-O. Couraud, et al. Design of fluorescently tagged poly(alkyl cyanoacrylate) nanoparticles for human brain endothelial cell imaging. Chem Commun. 2010;46:2602-4

44 Peracchia, M. T., E. Fattal, D. Desmaele, M. Besnard, J. P. Noel, J. M. Gomis, et al. Stealth (R) PEGylated polycyanoacrylate nanoparticles for intravenous administration and splenic targeting. J Control Rel. 1999;60:121-8

45 Lazarov, O., J. Robinson, Y.-P. Tang, I. S. Hairston, Z. Korade-Mirnics, V. M. Y. Lee, et al. Environmental Enrichment Reduces $A \beta$ Levels and Amyloid Deposition in Transgenic Mice. Cell. 2005;120:701-13

46 Valero, J., J. España, A. Parra-Damas, E. Martín, J. Rodríguez-Álvarez and C. A. Saura. Short-term Environmental Enrichment Rescues Adult Neurogenesis and Memory Deficits in APP Sw, Ind Transgenic Mice. PLoS One. 2011;6:e16832

47 Antunes, M. and G. Biala. The novel object recognition memory: neurobiology, test procedure, and its modifications. Cogn Process. 2012;13:93-110

48 McDonald, J. M., N. J. Cairns, L. Taylor-Reinwald, D. Holtzman and D. M. Walsh. The levels of water-soluble and triton-soluble $\mathrm{A} \beta$ are increased in Alzheimer's disease brain. Brain Res. 2012;1450:138-47

49 Robb, E., K. Perez, L. W. Hung, C. L. Masters, K. J. Barnham, R. A. Cherny, et al. High order W02-reactive stable oligomers of amyloid-beta are produced in vivo and in vitro via dialysis and filtration of synthetic amyloid-beta monomer. J Alzheimers Dis. 2015;44:69-78

50 Yoo, J.-W., E. Chambers and S. Mitragotri. Factors that Control the Circulation Time of Nanoparticles in Blood: Challenges, Solutions and Future Prospects. Curr Pharm Des. 2010;16:2298-307

51 Lundy, D. J., K.-H. Chen, E. K. W. Toh and P. C. H. Hsieh. Distribution of Systemically Administered Nanoparticles Reveals a Size-Dependent Effect Immediately following Cardiac Ischaemia-Reperfusion Injury. Sci Rep. 2016;6:25613

52 Kim, H. R., K. Andrieux, S. Gil, M. Taverna, H. Chacun, D. Desmaele, et al. Translocation of poly(ethylene glycol-co-hexadecyl)cyanoacrylate nanoparticles into rat brain endothelial cells: Role of apolipoproteins in receptor-mediated endocytosis. Biomacromolecules. 2007;8:793-9

53 Kim, H. R., S. Gil, K. Andrieux, V. Nicolas, M. Appel, H. Chacun, et al. Low-density lipoprotein receptor-mediated endocytosis of PEGylated nanoparticles in rat brain endothelial cells. Cell Mol Life Sci. 2007;64:356-64

54 Gartziandia, O., E. Herrán, J. A. Ruiz-Ortega, C. Miguelez, M. Igartua, J. V. Lafuente, et al. Intranasal Administration of Chitosan-Coated Nanostructured Lipid Carriers Loaded with GDNF Improves Behavioral and Histological Recovery in a Partial Lesion Model of Parkinson's Disease. J Biomed Nanotechnol. 2016;12:2220-80

55 Alexis, F., E. Pridgen, L. K. Molnar and O. C. Farokhzad. Factors Affecting the Clearance and Biodistribution of Polymeric Nanoparticles. Mol Pharm. 2008;5:505-15 